\title{
Synthesis and Crystal Structure of Elastin Sequence (Boc-Val-Pro-OBzl)
}

\author{
Beeranahally H. Doreswamy, ${ }^{*}$ Madegowda Mahendra, $*$ K. AbiraJ, ** D. Channegowda, ** \\ Sridhar M. ANANDALWAR, * and Javaregowda S. PRASAD** \\ *Department of Studies in Physics, University of Mysore, Manasagangotri, Mysore 570 006, India \\ **Department of Studies in Chemistry, University of Mysore, Manasagangotri, Mysore 570 006, India
}

\begin{abstract}
The fragments of elastin sequences of mammalian elastic protein elastins like Val-Pro were synthesized and characterized by X-ray crystallography. The sequence $\left(\mathrm{C}_{22} \mathrm{H}_{32} \mathrm{~N}_{2} \mathrm{O}_{5}\right)$ crystallizes in the orthorhombic space group $P 22_{1} 2_{1}$ with the parameters $a=6.2300(5) \AA, \quad b=11.3220(17) \AA, c=32.329(5) \AA, V=2280.4(5) \AA^{3}, Z=4$. The final $R$ factor is 0.694 . The structure has both intra and intermolecular hydrogen bonds.
\end{abstract}

(Received September 5, 2003; Accepted March 3, 2004; Published on Web May 21, 2004)

Elastic protein-based polymers have their origins in repeating sequences of the mammalian elastic protein. ${ }^{1}$ The parent polymers, (Val-Pro-Gly-Val-Gly) ${ }_{n}$ or poly(Val-Pro-Gly-ValGly), (Ala-Pro-Gly-Val-Gly-Val) $)_{n}$ or poly(Ala-Pro-Gly-ValGly-Val), (Val-Pro-Gly-Gly) ${ }_{n}$ or poly(Val-Pro-Gly-Gly) and (Val-Pro-Gly-Phe-Gly-Val-Gly-Ala-Gly) or poly(Val-Pro-GlyPhe-Gly-Val-Gly-Ala-Gly) derive from sequences that occur in all sequenced mammalian elastin protein. ${ }^{2,3}$ These polymers have a number of medical and non-medical applications. ${ }^{3}$

The synthesis of these elastic protein-based polymers by chemical synthesis has always been a challenge. The key to successful chemical synthesis is to stepwise build up the repeating sequence, taking care to ensure that the composite peptides are pure. Thus, racemization is a problem during the coupling to form Val-Pro and Ala-Pro, and the purification and crystallization of these dipeptides are critical to the optical purity of the pentamer. The absolute configuration of the title compound is known from the chemical evidence. The structure of the synthesized dipeptide was characterized by chemical analysis, optical rotation, ${ }^{1} \mathrm{H}-\mathrm{NMR}$ and ${ }^{13} \mathrm{C}-\mathrm{NMR}$. In this context, it is of interest to investigate the crystal structure of Boc-Val-Pro-OBzl (Fig. 1).

To Boc-Val-OH $(20 \mathrm{mmol})$, dissolved in acetonitrile $(35 \mathrm{~mL})$ and cooled to $0^{\circ} \mathrm{C}$, was added $N$-methylmorpholine (NMM) $(2.2$ $\mathrm{mL}, 20 \mathrm{mmol})$. The solution was cooled to $-15^{\circ} \mathrm{C} \pm 1{ }^{\circ} \mathrm{C}$ and isobutylchloroformate (IBCF) $(2.6 \mathrm{~mL}, 20 \mathrm{mmol})$ was added under stirring while maintaining the temperature at $-15^{\circ} \mathrm{C}$.

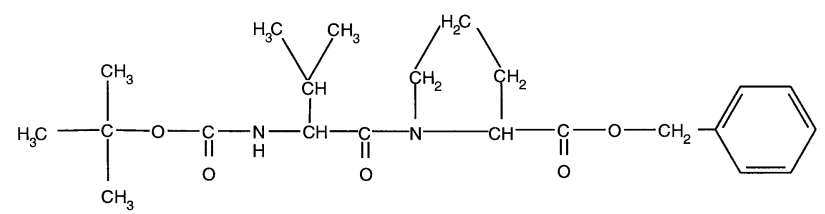

Fig. 1 Schematic diagram of the molecule.

To whom correspondence should be addressed.

E-mail: jsp@uomphysics.net
After stirring the reaction mixture for $10 \mathrm{~min}$ at this temperature, a pre-cooled solution of $\mathrm{HOBt}(3.1 \mathrm{~g}, 20 \mathrm{mmol})$ in DMF $(30 \mathrm{~mL})$ was added. The reaction mixture was stirred for an additional $10 \mathrm{~min}$ and a pre-cooled solution of $\mathrm{HCl}$. H-ProOBzl $(4.85 \mathrm{~g}, 20 \mathrm{mmol})$ and NMM $(2.2 \mathrm{~mL}, 20 \mathrm{mmol})$ in DMF $(40 \mathrm{~mL})$ was added slowly. After $20 \mathrm{~min}$, the $\mathrm{pH}$ of the solution was adjusted to eight by the addition of NMM and the reaction mixture was stirred overnight at room temperature. Acetonitrile was removed under reduced pressure and the residual solution was poured into about $400 \mathrm{~mL}$ of ice-cooled $90 \%$ saturated $\mathrm{KHCO}_{3}$ solution, and this mixture was stirred for $30 \mathrm{~min}$. The precipitate was filtered, washed with water, cold $1 \mathrm{M} \mathrm{HCl}$, water and finally dried. The crude peptide was recrystallized from ether and petroleum ether to obtain $6.58 \mathrm{~g}$ of Boc-Val-ProOBzl (yield, 90.8\%). $\quad R_{\mathrm{f}}^{1}, \quad 0.55 ; R_{\mathrm{f}}^{2}, \quad 0.68 . \quad[\alpha]_{\mathrm{D}}^{25}(\mathrm{C}, 1 ;$ $\mathrm{MeOH})-10.4$, m.p. $81-83^{\circ} \mathrm{C}$.

A single crystal of dimensions $0.25 \times 0.2 \times 0.2 \mathrm{~mm}$ was

Table 1 Crystallographic data

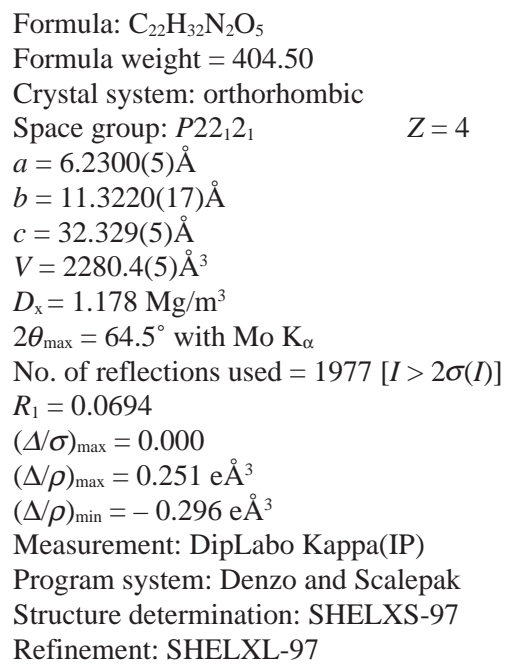

Formula: $\mathrm{C}_{22} \mathrm{H}_{32} \mathrm{~N}_{2} \mathrm{O}_{5}$

Formula weight $=404.50$

Space group: $P 22_{1} 2$

$c=32.329(5) \AA$

$V=2280.4(5) \mathrm{A}^{3}$

Mo K

$R_{1}=0.0694$

$(\Delta / \sigma)_{\max }=0.000$

$(\Delta / \rho)_{\max }=0.251 \mathrm{e}^{3}$

$(\Delta / \rho)_{\min }=-0.296 \mathrm{e}^{3}$

Measurement: DipLabo Kappa(IP)

Structure determination: SHELXS-97

Refinement: SHELXL-97 
Table 2 Atomic coordinates and equivalent thermal parameters

\begin{tabular}{rrrrr}
\hline Atom & \multicolumn{1}{c}{$x$} & \multicolumn{1}{c}{$y$} & \multicolumn{1}{c}{$z$} & \multicolumn{1}{c}{$U_{\text {eq }}$} \\
\hline C1 & $0.6374(11)$ & $0.1743(9)$ & $-0.02614(15)$ & $0.145(3)$ \\
C2 & $0.2488(9)$ & $0.1799(9)$ & $-0.01430(18)$ & $0.164(4)$ \\
C3 & $0.4715(19)$ & $0.3498(9)$ & $0.0043(2)$ & $0.185(4)$ \\
C4 & $0.4655(7)$ & $0.2208(6)$ & $0.00118(12)$ & $0.0889(19)$ \\
O5 & $0.4781(4)$ & $0.1653(3)$ & $0.04214(8)$ & $0.0835(11)$ \\
C6 & $0.6460(7)$ & $0.1828(6)$ & $0.06731(12)$ & $0.0828(17)$ \\
O7 & $0.8065(6)$ & $0.2373(5)$ & $0.05868(9)$ & $0.1177(18)$ \\
N8 & $0.6125(5)$ & $0.1261(4)$ & $0.10328(9)$ & $0.0780(13)$ \\
C9 & $0.7597(6)$ & $0.1362(5)$ & $0.13815(10)$ & $0.0722(14)$ \\
C10 & $0.8880(7)$ & $0.0230(5)$ & $0.14580(12)$ & $0.0786(16)$ \\
C11 & $1.0382(7)$ & $-0.0013(7)$ & $0.10940(17)$ & $0.109(2)$ \\
C12 & $0.7444(9)$ & $-0.0849(6)$ & $0.15314(14)$ & $0.0963(19)$ \\
C13 & $0.6306(6)$ & $0.1673(5)$ & $0.17611(11)$ & $0.0716(14)$ \\
O14 & $0.4383(4)$ & $0.1424(4)$ & $0.17921(8)$ & $0.0906(13)$ \\
N15 & $0.7333(5)$ & $0.2242(4)$ & $0.20721(8)$ & $0.0734(12)$ \\
C16 & $0.9555(6)$ & $0.2670(6)$ & $0.20742(12)$ & $0.0918(19)$ \\
C17 & $0.9849(8)$ & $0.3116(8)$ & $0.24980(16)$ & $0.129(3)$ \\
C18 & $0.7749(7)$ & $0.3349(6)$ & $0.26828(14)$ & $0.0933(18)$ \\
C19 & $0.6222(6)$ & $0.2485(5)$ & $0.24563(11)$ & $0.0739(15)$ \\
C20 & $0.5846(7)$ & $0.1394(7)$ & $0.26959(13)$ & $0.086(2)$ \\
O21 & $0.6618(7)$ & $0.0442(5)$ & $0.26354(11)$ & $0.1040(15)$ \\
O22 & $0.4535(5)$ & $0.1597(4)$ & $0.30190(9)$ & $0.0965(13)$ \\
C23 & $0.4229(9)$ & $0.0656(7)$ & $0.33128(17)$ & $0.115(2)$ \\
C24 & $0.6124(9)$ & $0.0453(7)$ & $0.35864(14)$ & $0.0898(19)$ \\
C25 & $0.7347(10)$ & $0.1390(7)$ & $0.37235(14)$ & $0.0998(19)$ \\
C26 & $0.9087(11)$ & $0.1181(9)$ & $0.39760(17)$ & $0.122(3)$ \\
C27 & $0.9659(13)$ & $0.0066(12)$ & $0.4099(2)$ & $0.133(4)$ \\
C28 & $0.8433(17)$ & $-0.0838(10)$ & $0.3967(2)$ & $0.143(4)$ \\
C29 & $0.6674(13)$ & $-0.0686(8)$ & $0.37067(18)$ & $0.118(3)$ \\
& & & & \\
\hline
\end{tabular}

$U_{\mathrm{eq}}=(1 / 3) \sum_{i} \Sigma_{j} U_{i j}\left(a_{i} * a_{j} *\right)\left(\boldsymbol{a}_{i} \cdot \boldsymbol{a}_{j}\right)$.

chosen for X-ray diffraction studies. The measurements were made on a DIPLabo Imaging Plate system with graphite monochromated radiation $\left(\mathrm{Mo} \mathrm{K}_{\alpha}\right.$ ). The structure was solved and refined using the SHELX-975 program. All the nonhydrogen atoms were revealed in the first map. Full-matrix least-squares refinement based on 1977 observed reflections ( $I>$ $2 \sigma(I)$ ) with isotropic temperature factors for all the atoms converged residual to $R=0.1455$. Refinement of non-hydrogen atoms with anisotropic thermal parameters was started at this stage. After eight cycles of refinement the residuals saturated at $R=0.0694$ for 1977 observed reflections and 263 parameters. The hydrogen atoms were placed at calculated positions and were not refined. Table 1 gives the details of crystal data, data collection and refinement.

The final positional coordinates with equivalent isotropic temperature factors for all the non-hydrogen atoms are listed in Table 2. The bond lengths and bond angles agree with their standard values. Figure 2 represent the ORTEP diagram of the molecules at $50 \%$ probability. The molecules appear stacked and exhibits layer-type polymeric structure when viewed along the $b$ axis. The structure has both intra and intermolecular hydrogen bonds of the type $\mathrm{C}-\mathrm{H} \cdots \mathrm{O}$. C1-H16A $\cdots \mathrm{O} 7$

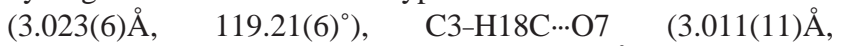
$\left.119.34(5)^{\circ}\right)$ and $\mathrm{C} 28-\mathrm{H} 5 \cdots \mathrm{O} 7 \quad\left(3.308(11) \AA, \quad 137.12(9)^{\circ}\right)$,

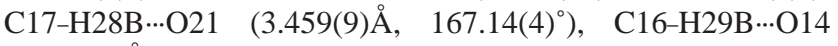
(3.445(5) $\left.\mathrm{A}, 148.09(3)^{\circ}\right)$ with symmetry codes $(2-\mathrm{x},-1 / 2+\mathrm{y}$, $1 / 2-\mathrm{z}),(2-x, 1 / 2+y, 1 / 2-z),(1+\mathrm{x}, \mathrm{y}, \mathrm{z})$ respectively. The dihedral angle found between least-squares planes $1(\mathrm{C} 24 \mathrm{C} 25$ C26 C27 C28 C29) and 2(N15 C16 C17 C18 C19) is 82.9(3) ${ }^{\circ}$,

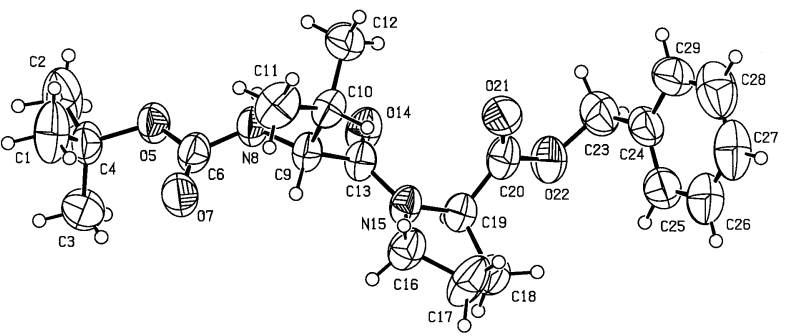

Fig. 2 ORTEP of the molecule at $50 \%$ probability.

with a maximum deviation of $0.157(6) \AA$ for $\mathrm{C} 18$.

The bond lengths and angles of the peptide link are in conformity with those of similar molecules. ${ }^{6}$ The peptide bond between $\mathrm{C} 13-\mathrm{N} 15$ is $1.355(5) \AA$ and between $\mathrm{C} 13-\mathrm{O} 14$ is $1.235(4) \AA$. Such values are expected in peptide linkages. The conformation of the dipeptide is identified by the following rotations: the rotations about $\mathrm{C} 13-\mathrm{C} 9, \mathrm{~N} 8-\mathrm{C} 9$ and $\mathrm{C} 13-\mathrm{N} 15$ are respectively $\psi=-155.13^{\circ}, \phi=129.22^{\circ}$ and $\omega=-175.39^{\circ}$.

\section{Acknowledgements}

The authors would like to express their thanks to DST, Government of India for financial assistance under the project SP/I2/FOO/93.

\section{References}

1. (a) L. B. Sandberg, J. G. Leslie, C. T. Leach, V. L. Torres, A. R. Smith, and D. W. Smith, Pathol. Biol., 1985, 33, 266. (b) H. N. Yeh, Ornstein-Goldstein, Z. Indik, P. P. Shepperd, N. Anderson, J. C. Rosenbloom, G. C. Cicila, K. Yoon, and J. Rosenbloom, Collagen Rel. Res., 1987, 7, 235.

2. Z. Indik, H. N. Yeh, Ornstein-Goldstein, P. Sheppard, N. Anderson, J. Rosenbloom, L. Peltonen, and J. C. Rosenbloom, Proc. Natl. Acad. Sci., USA, 1987, 84, 5680.

3. L. B. Sandberg, W. R. Gray, J. A. Foster, A. R. Torres, V. L. Alvarez, and J. Janata, Adv. Exp. Med. Biol., 1977, 79, 277.

4. D. W. Urry, A. Nicol, D. C. Gowda, L. D. Hoban, A. McKee, T. Williams, D. B. Olsen, and B. A. Cox, In "Medical applications of bioelastic materials", C. G. Gebelein (ed.), Technomic Publishing, Atlanta, Georgia, 1993, 82-103.

5. (a) G. M. Sheldrick, 1997. SHELXS-97. Program for Crystal Structure Solution. University of Göttingen, Germany. (b) G. M. Sheldrick, 1997. SHELXL-97. Program for the Refinement of Crystal Structures. University of Göttingen, Germany.

6. (a) L. Pauling and R. B. Corey, Proc. Nat. Acad. Sci. USA., 1951, 37, 729. (b) L. Pauling, R. B. Corey and H. R. Branson, Proc. Nat. Acad. Sci. USA., 1951 37, 205. 